\title{
ONLINE COURSE DESIGN AND MATERIALS DEVELOPMENT FOR TEACHING READING OF RESEARCH ARTICLES TO EFL UNDERGRADUATE STUDENTS AT A GREEK TECHNICAL UNIVERSITY
}

\author{
Emmanuela Seiradakis ${ }^{1}$, Ioannis Spantidakis ${ }^{2}$ \\ ${ }^{1}$ School of Education, University of Crete \& Language Center, Technical University of Crete \\ ${ }^{2}$ School of Education, University of Crete, Greece \\ Phone: 2821037338,E-mail:eseiradaki@isc.tuc.gr
}

\begin{abstract}
Recent research findings suggest that reading research articles (RAs) enhances undergraduate engineering students' technical knowledge and fosters their lifelong learning skills. Nevertheless, the RA genre inherently displays challenging features for novice readers, especially EFL readers. Previous works on developing materials for teaching the reading of RAs to undergraduate students are limited and mostly report on the effectiveness of interventions rather than on course design and materials development. This paper presents the design and development of online materials for a Moodle-based, English for Specific Academic Purposes course that aimed to help Greek undergraduate Electrical and Computer Engineering (ECE) students to learn how to read RAs within their field. The materials design was based on the theories of genre analysis, metacognition and cognitive apprenticeship. Initially, a small RA corpus consisting of thirty RAs from high-ranking ECE journals and conferences from IEEE, ACM, Elsevier and Springer was created in cooperation with the ECE faculty. Subsequently, a move analysis was performed based on a simplified coding scheme of rhetorical moves in the target genre adjusted to the needs of novice Greek EFL readers. The results from our corpus analysis were used as the foundation of the genre-based materials that aimed at fostering learners' declarative, procedural and conditional genre knowledge and included various examples of move structures and patterns, terminology, grammar as well as weekly genre analysis reflective tasks. We then created materials that intended to provide further support so that students could convert their newly acquired genre knowledge into procedural knowledge and explicitly taught top-down RA expeditious reading strategies and conditional knowledge by including metacognitive strategy training that intended to raise their awareness of when and why they should use the taught strategies. In an attempt to further tailor the materials to the needs of our students we included audiovisual enhancements in both L1 and L2 for presentation and feedback purposes, metacognitive prompts, online dictionaries and concordancers.
\end{abstract}

Key words: online materials, research article genre, metacognition, reading, undergraduates, engineering 


\section{INTRODUCTION}

The ability to read research articles (RAs) is considered of vital importance for engineering undergraduate students as it enhances their technical knowledge and most importantly it fosters their lifelong learning skills (Kuxhaus \& Corbiere 2016) as outlined by ABET, the American Accreditation Board for Engineering and Technology (Felder \& Brent 2003). Nevertheless, relevant findings suggest that undergraduates and especially NNS students, regardless of their discipline, usually face difficulties in reading the particular genre mainly due to their lack of RA genre schema (Bitran et al. 2012; Negretti \& Kuteeva 2011). ESP school genre-based tasks (Swales 1990; 2004) can facilitate novices' reading of newly encountered academic genres by raising "their rhetorical consciousness" (Swales 1990: p.213), although recent findings suggest their effectiveness both in reading and writing RAs largely depends on whether they are underpinned by the theory of metacognition (Negretti, \& Kuteeva 2011). Other than Negretti \& Kuteeva (2011), whose study focused on second-year pre-service English teachers, previous works on integrating the theories of genre and metacognition have focused on developing postgraduate students' RA academic writing abilities within traditional courses and have mainly investigated the effectiveness of specific interventions, rather than reflecting on course design and material development (Negretti 2012; 2017; Negretti \& McGrath 2018; Yeh 2014). Works that have focused on genre analysis and online materials development for specific disciplines (Chang \& Kuo 2011; Stoller \& Robinson 2013) have also targeted RA academic writing of advanced learners. To bridge the aforementioned gaps, this paper reports on the process of designing an online English for Specific Academic Purposes (ESAP) course that aimed to help Electrical and Computer Engineering (ECE) undergraduate students at the Technical University of Crete (TUC) to learn how to read RAs. We initially present the process of compiling and coding the 30 ECE RAs that functioned as our "RA pool" for creating the online materials and subsequently describe the resulting online course and its theoretical underpinnings.

\section{RA CORPUS COMPILATION \& MOVE TAGGING}

The RA corpus included articles from a variety of ECE related journals and subdisciplines. The underpinning pedagogical rationale was that this ECE cross-disciplinary genre analysis would minimize the danger of students perceiving the RA genre as a "mould" (Reimes 1991) and would better prepare them for coping with the highly diverse nature of ECE RAs after course completion. The RA selection entailed a long-term iterative process that involved the ECE faculty members initially selecting specific RAs from a range of high-ranking journals in IEEE, ACM, Elsevier and Springer based on a specific set of criteria outlined at the beginning of the process. The authors of the present paper subsequently coded each article and then had several meetings in order to validate the coded moves with at least two subject specialists (faculty members, TAs, or PhD students) specialized in the respective sub-discipline to which the RA belonged. Although this was a lengthy process lasting over a rear, it was deemed necessary as relevant literature suggests that especially in highly technical fields such as engineering, collaboration with "insiders" is of vital importance for determining which specific articles should be used. Another consideration was that since EAP instructors do not 
belong to the engineering discourse community of the target texts, they may face difficulties in analyzing the articles (Maswana et al 2015).

Move coding was based on content and, wherever applicable, on the linguistic move manifestations in each article. It entailed a top-town and bottom-up process of Swalesian move analysis (1990;2004) as outlined by Cortes (2007) and Nwogu (1997) based on a literature-based modified coding scheme (Table 1), specialized for ECE related disciplines (Anthony 1999; Chang \& Kuo 2011; Han et al. 2010; Hyppönen \& Paganuzzi; Kanoksilapatham 2012, 2015; Maswana et al 2015; Posteguillo 1999). To adjust the coding scheme to our students' ZPD we followed the lead of previous researchers who have also used move analysis for pedagogical purposes (Chang \& Kuo 2011; Stoller \& Robinson 2013) and made modifications to Swale's original terminology. Thus, we included only the term move rather than steps and narrowed down the analysis to major RA macro-moves (moves that occur in more than one RA sections) and major moves occurring in specific sections.

Table 1 Coding Scheme

\begin{tabular}{|c|c|c|c|c|c|c|}
\hline Major Moves & A & I\&RW & $\mathrm{M}$ & $\mathrm{R}$ & $\mathrm{D}$ & $\mathrm{C}$ \\
\hline Background (Relevant background information) & $\mathrm{AB}$ & IB & MB & RB & DB & $\mathrm{CB}$ \\
\hline Relevant Literature Reference & ARL & IRL & MRL & RRL & DRL & CRL \\
\hline Gap & AG & IG & MG & - & - & - \\
\hline Purpose & $\mathrm{AP}$ & IP & MP & $\mathrm{RP}$ & DP & $\mathrm{CP}$ \\
\hline Methods & $\mathrm{AM}$ & IM & MM & & $\mathrm{DM}$ & $\mathrm{CM}$ \\
\hline Methods-Subjects or Samples & & & MS & & & \\
\hline Methods- Procedure & & & MPo & & & \\
\hline Methods-materials and equipment & & & MM & & & \\
\hline Methods-equations/variables/definitions/ tests & & & ME & & & \\
\hline Major Results & AMR & IMR & - & RMR & & \\
\hline $\begin{array}{l}\text { Discussion } \\
\text { (interpretation/comparison with other works) }\end{array}$ & & & MD & & DD & $\mathrm{CD}$ \\
\hline $\begin{array}{l}\text { Evaluation (evaluation of results, partial /complete } \\
\text { conclusion) }\end{array}$ & $\mathrm{AE}$ & IE & ME & $\mathrm{RE}$ & $\mathrm{DE}$ & $\mathrm{CE}$ \\
\hline Implications of Results & & & MIm & & DIm & CIm \\
\hline Limitations of Study & & & Mlim & & Dlim & Clim \\
\hline
\end{tabular}

$\mathrm{A}=\mathrm{Abstract}, \mathrm{I} \& \mathrm{RW}=$ Introduction \&Related Work, M=Methods, $\mathrm{R}=$ Results, D-Discussion,

$\mathrm{C}=$ Conclusion

After reaching a consensus with the ECE insiders on the coded moves of a specific RA, the RA PDF file was converted into a word document file with the moves tagged at the beginning of each move and fed on AntCon free software. In this way, we could identify multi-move patterns and cycles and their lexico-grammatical features for developing rhetorical move organizers for each RA section or combined sections, wordlists with move key words and bundles and other genre analysis and reading tasks for our online course.

Similar to previous findings (Anthony 1999; Chang \& Kuo 2011; Han et al. 2010; Hyppönen \& Paganuzzi; Kanoksilapatham 2012, 2015; Maswana et al 2015; Posteguillo 1999), our results indicated that 29 out of the 30 ECE RAs did not display explicit IMRD organization. More specifically, the only two sections that appeared to be relatively stable and bear generic headings were the Introduction and the Conclusion, whereas the sections 
in between (Method, Results, and Discussion) were often mixed, merged and commonly carried article-related headings and sub-headings. Out of all the IMRD sections, the M\&M section appeared to have the most diverse organizational and rhetorical structure commonly involving more than one section, which also included several sub-sections within the same RA.

\section{ONLINE COURSE DESIGN \& MATERIALS DEVELOPMENT}

The experimental online course was constructed on the university's Moodle platform and included fifteen separate online labs. The course design was theoretically underpinned by the concept of metacognitive genre awareness (Negretti 2012; 2017; Negretti, \& Kuteeva 2011; Negretti \& McGrath 2018; Yeh 2014) which combines the theories of ESP school genre analysis (Swales 1990; 2004) and metacognition (Flavell 1979).

Since our students were novices and had limited exposure to the particular genre, the first part of the course aimed at enhancing the four dimensions of their genre knowledge based on Tardy's model (2009). Accordingly, online materials primarily attempted to enhance students' Formal \& Rhetorical RA genre knowledge (purpose, organization, structure, lexico-grammatical features, rhetorical moves, common rhetorical patterns and cycles of each RA section), Process genre knowledge (practices related to the process of writing for RAs for publication, reception of the RA genre within the wider RA publishing industry, the role of authors, journal editors and reviewers) and Content genre knowledge (the typical topic focus of the RA genre as a whole and its sub-genres combined with ECE subdisciplines, their related journals and conferences).

The first two online genre labs focused on familiarizing students with the concept of Swalesian genre analysis and the RA macrostructure respectively, whereas the subsequent six labs were arranged around the RA sub-genres of Abstract, Introduction, M\&M, Results, Discussion, R\&D (Combined Results and Discussion sections) \& Conclusion. The second part of the course (Labs 8-15) aimed at providing further support to students to convert their newly acquired RA declarative genre knowledge into procedural knowledge, i.e., tangible online RA reading strategies experts use such as paying attention to the RA source, previewing, predicting, skimming, search reading, scanning, browsing, online RA searching (Knezek 2015; Urquhart \& Weir 2014 ) and conditional knowledge i.e. explicit metacognitive training on when and why students should use these strategies and how to plan, orchestrate, monitor and regulate the taught strategies (Flavell 1979).

The implementation of each lab was based on the model of cognitive apprenticeship (Collins et al. 1991) adjusted to web-based environments (Spantidakis et al. 2014). Thus, each lab initially included online modeling affordances, coaching and scaffolding tasks as well as articulation and reflection tasks. Research based guidelines and principles on how to utilize Moodle administrative tools, content creation, delivery tools as well as collaborative and communication tools, learning tools, and assessment tools were purposefully utilized in order to create a course that would support students' selfregulation processes (Dabbagh \& Kitsantas 2013). 


\subsection{Modeling}

The modeling phase of each lab included specially-made online instructional L1 and L2 videos as well as static representations of RA genre analysis and reading strategies on authentic RAs taken from the corpus.

Online "RA Writerly Reader Videos" (Lab 1-Lab 8) offered audiovisual think-aloud cognitive modeling of genre-analysis processes, whereas the "RA Reader Videos" (Lab 815) provided think-alouds of RA metacognitive reading strategies (Labs 8-15). All videos were created with Camtasia screencast software which offered our students the ability to simultaneously observe both which part of the RA text was read and which genre or reading strategy was used. The videos purposefully included common mistakes and problems encountered whilst performing genre analysis or when reading an RA which allowed the researcher to model problem-solving strategies during genre-analysis or RA online reading. The design and production of the screencasts followed literature-based principles and guidelines for maximizing student learning from video content (Brame 2016; Mayer 2001;2008; Mayer\& Johnson 2008; Mayer \& Moreno 2003). The first author who also was the instructor of the course, appeared in the videos, since the presence of the teacher in educational videos seems to enhance university students' positive socio-emotional responses (Guo et al. 2014; Kizilcec et al. 2014) and supports learners' understanding by providing nonverbal modalities of interaction (Clark \& Mayer, 2016).

To make viewing more active, all videos were accompanied by Camtasia built-in online quizzes, extra Moodle quizzes and other video-related tasks such as concept map creation based on the video content. All videos included interactive features such as online content to give more control to the students.

Static modeling representations of RA genre knowledge included notes with detailed descriptions of the purpose, the content and the information structure relating to the RA macrostructure and RA sub-sections. Moreover, each lab included several rhetorical move graphic organizers, picturing possible multi-move patterns and cycles for the corresponding section, original RA PDFs from the corpus marked with all the major moves, lists with multiple examples of moves, move patterns and their possible linguistic materializations and finally, online concept maps depicting how the four facets of genre knowledge interrelate and overlap directly effecting the RA rhetorical information structure, language and style.

\subsection{Coaching}

Coaching tasks initially aimed at providing structured support in order for learners to build RA declarative genre knowledge. Subsequently, these tasks intended to encourage learners to purposefully access and explicate what they learned about the RA genre and reflect on how they could use it in making decisions in their own reading context, i.e., to make their newly acquired RA genre knowledge metacognitive. Therefore, the coaching phase initially involved multiple genre-related tasks integrated into more than 40 Moodle quizzes with around 900 different quiz questions (multiple-choice questions, matching tasks, drag and drop tasks, sequencing tasks, fill in tasks, labeling and essay questions) ranging from easy to more challenging as we attempted to customize as much as possible the learning content in order to meet individual learner needs, abilities and learning styles (McDonough \& Shaw 2012). These quizzes focused on tasks initially targeting genre theory content, albeit the majority of them included tasks focusing on formal and rhetorical 
genre knowledge with multiple examples taken from the RA corpus. Some questions also included the use of web-based concordancers. For example, the WriteAhead concordancer (Liou et al.2012) was used for students to answer lexico-grammatical questions on a move's materializations. Moodle quiz questions further included comparative genre analysis tasks of authentic flowed RA exemplars mostly taken from conferences as opposed to proficient works taken from the RA corpus and required students to write short rationale statements on the reasons they thought these exemplars were flowed or proficient based on their formal and rhetorical features. Moreover, Moodle online concept map tasks were used for students to visualize their genre knowledge and/or analysis. After completing the aforementioned tasks, participants were required to write a short reflective account integrated as a Moodle quiz essay question. In this question, students were required to describe: 1) what they learned (declarative knowledge), 2) how they thought their newly acquired genre knowledge could facilitate their RA reading (procedural genre knowledge), and 3) when and why they could use this knowledge in their specific reading context at TUC (conditional genre knowledge), i.e., how RA genre knowledge could function as a tool for reading RAs at the undergraduate level.

Moodle forums offered a supplementary source of metacognitive genre coaching reference in the form of fellow classmates. Throughout the coaching tasks there were social prompts, encouraging students to use the forum in order to upload their responses and exchange ideas. By uploading their responses to the genre-based tasks, and sharing their thoughts online, the students were not only able to report the moves that they identified in a task, but they were also able to access each other's postings, self-monitor their own genre observations and subsequently monitor the observations of their fellow classmates.

Labs 8-15 respectively included coaching tasks focusing on how to convert RA genre knowledge into purposeful metacognitive reading strategies. Thus, after the modeling phase, students were required for example to create concept maps depicting what reading strategies they would use in order to grasp the gist of an RA quickly (for example checking the source, activating prior genre knowledge, previewing, skimming or careful reading of the Abstract, the Introduction and the Conclusion) combined with metacognitive strategies (planning, reading and deciding on a specific strategy or combination of strategies, deciding on which sections they would focus, monitoring the implementation of strategies, regulating and orchestrating strategies and finally evaluating their strategies' effectiveness). Subsequent coaching tasks entailed reading tasks with RAs taken from the corpus integrated into Moodle quizzes. These tasks required the application of one or multiple taught strategies under tight time limits. For example, skimming tasks involved summarizing whole RAs or RA sections or labeling RA paragraphs/sections. Search reading tasks included questions prompting students to locate answers in one or multiple RAs. Similar to genre labs, after completing coaching tasks, students were required, once again, to write a short account reflecting on the strategies they had learned, how they could apply them, and most importantly, when and why they should implement them.

\subsection{Scaffolding}

Scaffolding genre tasks for the first part of the course (Labs 1-8) mostly involved collaborative group assignments integrated into Moodle that aimed at facilitating the coconstruction of RA genre knowledge whilst simultaneously nurturing the groups' co and shared metacognitive regulation sub-processes of planning, monitoring and evaluation (Hadwin et al. 2017; Iskala et al. 2015). 
Wikis were purposefully selected since their supporting "show different functions" and "wiki comments" combined with online forums have been found effective in helping computer science undergraduates engage in metacognitive behaviors (Vivian et al. 2013). Embedded metacognitive prompts in the wikis' initial page explicitly encouraged groups to plan their tasks (watch the online Videos, read the notes/graphic organizers etc.), monitor their progress (apply their genre knowledge and construct the genre analysis wiki, actively assessing their genre construction processes), evaluate their analysis and finalize it. Upon the completion of each task, another group was assigned as a "Reviewer" and had access to the specific collaborative wiki. This group evaluated and reviewed the assignment and provided feedback.

Collaborative wiki assignments involved reports focusing on specific facets of genre knowledge. For example, in Move Analysis Reports (MARs), the groups were assigned an RA from the corpus and were required to name a move, outline its content, define its purpose and analyze language features and discipline specific practices in the ECE field (Peacock 2011; Cheng 2008). Collaborative scaffolding tasks further included comparative analysis of multiple RAs from our corpus stemming from different ECE journals and sub-disciplines. In these tasks, students compared and analyzed two to three RAs and reflected on the structural, rhetorical, lexico-grammatical differences and/or similarities (formal and rhetorical knowledge) between ECE journals with different foci and their respective sub-disciplines (process and content genre knowledge).

Comparative analysis wiki tasks further included cross-genre awareness tasks (Hyland 2004; Hyon 2001), in which groups were required to compare RAs from the corpus to the Lab Reports they were writing for their core courses during the respective semester (Advanced Logic Design, Programming and Physics). In these tasks, groups were asked to reflect on how the RA genre macrostructure (Lab 2) and each of its sub-genres (Labs 3-Lab 8) differed or were similar compared to the macro-structure and the sub-genres of the Lab Report in terms of the rhetorical triangle of author, audience, purpose, their respective rhetorical moves and their lexicogrammatical features. Lastly, collaborative scaffolding wiki tasks included assignments where the groups had to write their own RAsub-genres based on imaginary RA titles for ECE journals or student conferences. As artificial as this task may initially appear, we suggest that through this process our students were offered an opportunity to implement their formal and rhetorical genre knowledge and undergo RA authors' metacognitive stages of planning, monitoring and evaluating, reviewing and revising, whilst taking into consideration each sub-genre's purpose, content and audience expectations (process and content genre knowledge).

For the second part of the course, collaborative scaffolding wikis and quizzes entailed groups locating online RAs from specific professors and labs within the ECE school at TUC and subsequently applying a single strategy or a combination of the reading strategies taught in order to write sub-section summaries, label paragraphs, answer questions based on a single or multiple RAs and so on. Collaborative online concept maps and/or short wiki reports were also used as a tool for the groups to reflect on the difficulties they faced, the reading strategies they used in order to overcome these difficulties as well as on the articles' rhetorical structure and content. In this way, groups were stimulated to articulate and reflect both on their reading strategies and the RAs in accordance with previous works on reading courses within the higher education context which propose that discussing primary literature may be an effective method for facilitating the understanding of the text (Hoskins et al. 2011; Van Lacum et al. 2014). 


\subsection{Fading out}

Final genre-lab tasks mostly included individual genre analysis wiki reports encompassing all genre knowledge facets without explicit support. These wiki assignments were open to other students, who could review the analysis and provide feedback. More advanced, optional fading out tasks entailed students finding "proficient" and "flowed" samples of whole RAs or the respective RA sub-genre taught in a specific lab and writing reflective reports. Fading out tasks for the second part of the course involved students locating RAs of their own interests, applying skimming and search reading strategies and reflecting on how they accomplished the task. Moreover, the students created presentations of their RAs in the form of webcasts and uploaded them in Moodle.

\subsection{Articulation \& Reflection}

Metacognitive student journals were integrated as compulsory weekly Moodle quizzes. Each journal included prompts encouraging students to reflect on specific points, as relevant research suggests that structured journals are more effective in triggering novices' critical reflection (Cornish et al. 2008; Dunlap 2006; Harris 2008) and contribute to reducing the "blank journal syndrome" (Gulwadi 2009). The prompts encouraged students to specifically reflect on what they had learned in the specific lab, identify points of confusion and their possible underlying reasons, describe how they intended to clarify them, and lastly identify possible applications of what they learned.

\section{COMPLEMENTARY ONLINE METACOGNITIVE SCAFFOLDS}

\subsection{Metacognitive Prompts}

Metacognitive prompts were embedded in videos, quizzes and wikis as relevant research findings suggest that they are effective in enabling university students to activate their metacognitive activities (Bannert et al. 2009; Bannert \& Mengelkamp 2013). These prompts were intended to facilitate students' monitoring and control of their genre and/or reading strategy information processing by triggering metacognitive and regulative processes of goal setting, planning, monitoring, control and evaluation strategies. For example, the following planning prompts appeared as the initial quiz questions of an M\&M move analysis task: "What is my goal for this task?", "What do I already know about the M\&M section?", "What is the communicative purpose of this section? Is it a general or specific RA section?", "Do I remember the basic M\&M moves? Should I check the videos, the notes or the M\&M rhetorical move organizers?". Monitoring prompts were integrated for example as animations and/or as Camtasia's built-in quizzes within modeling videos, as well as in Moodle quizzes. For example, in the "RA Writerly Video" of the Introduction Lab, during the video, at specific points the following questions appeared as a Camtasia embedded quiz: "Have I understood the function of the GAP move?", "Do I need to watch this part again?". Evaluation prompts were integrated as final quiz questions and intended to help learners evaluate their genre and/or reading problem-solving processes by encouraging them to consider various perspectives related to their solutions and processes. For example, after a Results section move analysis task the following questions appeared: "Does my move analysis make sense?", “Am I satisfied from the way I faced the task? Have I included 
all the moves I wanted?", "Do I need to modify my analysis?". As mentioned earlier, prompts were also included within collaborative wikis, urging group members to decide on their planning strategy (How are we going to do this?), to monitor their ongoing processes (Are we achieving our goals?) and to evaluate their performance (Are we satisfied with our report?).

\subsection{Feedback}

Within the presented course, feedback was seen as an evaluation strategy and as such, it was designed in an interactive way in order to foster students' metacognitive processes. Therefore, other than direct, explicit text-based feedback, we made an effort wherever possible to create specially designed Camtasia feedback screencasts that have been found to be effective in raising students' awareness of their ineffective thinking strategies (Harper et al 2015; Marriott \& Teoh, 2012; Silva, 2012; Thompson \& Lee, 2012; Vincelette \& Bostic, 2013). In designing these screencasts, we took into consideration the noticing hypothesis and attention theory and made an effort to use Camtasia's functions to draw students' attention to specific points. Feedback videos initially praised students for their efforts and subsequently included comments adjusted to specific grade ranges, with tailor-made advice on how students could improve their performance.

\section{CONCLUSION}

This paper presented the process of designing an online EAP course intended to sensitize Greek undergraduate ECE students to the RA genre. It provided an account of the initial stages of creating a small a corpus of $30 \mathrm{RAs}$, and discussed the course design and materials development underpinned by the theories of genre, metacognition and cognitive apprenticeship. Arguably, this study exhibits several limitations. Firstly, the size of the RA corpus was rather limited and the articles were not random as our target learners were novices and specific criteria had to be fulfilled in order for the RAs to fit their ZPD. Secondly, there was no formal assessment of the course's effectiveness of students' RA reading strategies. Nevertheless, we believe that the proposed course can offer insights into how EAP teachers who wish to familiarize their undergraduate students with the RA genre can utilize corpus tools and design metacognitive genre materials using a free LMS such as Moodle.

\section{REFERENCES}

Anthony, L (1999) "Writing research article introductions in software engineering: How accurate is a standard model?," IEEE transactions on Professional Communication, vol.42(1), pp.38-46, 1999.

Anthony, L. (2014). AntConc (Version 3.4.3) [Computer Software]. Tokyo, Japan: Waseda University. Retrieved from http://www.laurenceanthony.net/

Bannert, M., Hildebrand, M., \& Mengelkamp, C. (2009). Effects of a metacognitive support device in learning environments. Computers in Human Behavior, 25(4), 829835. 
Bannert, M., \& Mengelkamp, C. (2013). Scaffolding hypermedia learning through metacognitive prompts. In International handbook of metacognition and learning technologies (pp. 171-186). Springer, New York, NY.

Bitran, M., Zúñiga, D., \& Leiva, I. (2012). Reading Strategies used by Undergraduate Medical Students to Comprehend Scientific Publications. Medical Science Educator, 22(3), 147-150.

Brame, C. J. (2016). Effective educational videos: Principles and guidelines for maximizing student learning from video content. CBE-Life Sciences Education, 15(4), es6.

Chang, C. F., \& Kuo, C. H. (2011). A corpus-based approach to online materials development for writing research articles. English for Specific Purposes, 30(3), 222-234.

Cheng, A. (2008). Analyzing genre exemplars in preparation for writing: The case of an L2 graduate student in the ESP genre-based instructional framework of academic literacy. Applied linguistics, 29(1), 50-71.

Clark, R. C., \& Mayer, R. E. (2016). E-learning and the science of instruction: Proven guidelines for consumers and designers of multimedia learning. John Wiley \& Sons.

Collins, A., Brown, J. S., \& Holum, A. (1991). Cognitive apprenticeship: Making thinking visible. American educator, 15(3), 6-11.

Cornish, M. M., \& Cantor, P. A. (2008). "Thinking About Thinking: It's not Just for Philosophers:" Using Metacognitive Journals to Teach and Learn About Constructivism. Journal of Early Childhood Teacher Education, 29(4), 326-339.

Cortes, V. (2007). Genre and corpora in the English for academic writing class. Ortesol Journal, 25, 9.

Dabbagh, N., \& Kitsantas, A. (2013). Using learning management systems as metacognitive tools to support self-regulation in higher education contexts. In International handbook of metacognition and learning technologies (pp. 197-211). Springer, New York, NY.

Dunlap, J. C. (2006). Using guided reflective journaling activities to capture students' changing perceptions. TechTrends, 50(6), 20-26.

Felder, R. M., \& Brent, R. (2003). Designing and teaching courses to satisfy the ABET engineering criteria. Journal of Engineering Education, 92(1), 7-25.

Flavell, J. H. (1979). Metacognition and cognitive monitoring: A new area of cognitivedevelopmental inquiry. American psychologist, 34(10), 906.

Guo, P. J., Kim, J., \& Rubin, R. (2014, March). How video production affects student engagement: An empirical study of mooc videos. In Proceedings of the first ACM conference on Learning@ scale conference (pp. 41-50). ACM.

Gulwadi, G. B. (2009). Using reflective journals in a sustainable design studio. International Journal of Sustainability in Higher Education, 10(2), 96-106.

Hadwin, A. F, Järvelä, S., \& Miller M. (2017). Self-regulation, co-regulation, and shared regulation in collaborative learning environments. In Handbook of self-regulation of learning and performance (pp. 65-86). New York, NY Routledge.

Han, P., Zhu, Z., \& Wei, Q. (2010, December). An Analysis of Disciplinary Variation in the Structure of Research Article Introductions. In Computational Intelligence and Software Engineering (CiSE), 2010 International Conference on (pp. 1-4 IEEE.

Harper, F., Green, H., \& Fernandez-Toro, M. (2015). Using screencasts in the teaching of modern languages: investigating the use of Jing ${ }^{\circledR}$ in feedback on written assignments. The Language Learning Journal, 1-18. 
Harris, M. (2008). Scaffolding reflective journal writing-Negotiating power, play and position. Nurse education today, 28(3), 314-326.

Hoskins, S. G., Lopatto, D., \& Stevens, L. M. (2011). The CREATE approach to primary literature shifts undergraduates' self-assessed ability to read and analyze journal articles, attitudes about science, and epistemological beliefs. CBE-Life Sciences Education, 10(4), 368-378.

Hyland, K. (2004). Genre and second language writing. Ann Arbor, MI: University of Michigan Press.

Hyon, Genre and ESL Reading, in Johns, A. M. (Ed.). (2001). Genre in the classroom: Multiple perspectives

Hyppönen, K., \& Paganuzzi, V. M. (2010). Computer science research articles: the locations of different section types, and a proposal for standardization in the structure. Scientometrics, 84(1), 199-220. Routledge, 121-??

Iiskala, T., Volet, S., Lehtinen, E., \& Vauras, M. (2015). Socially Shared Metacognitive Regulation in Asynchronous CSCL in Science: Functions, Evolution and Participation. Frontline Learning Research, 3(1), 78-111

Kanoksilapatham, B. (2012). Research article structure of research article introductions in three engineering subdisciplines. IEEE Transactions on professional communication, 55(4), 294-309.

Kanoksilapatham, B. (2015). Distinguishing textual features characterizing structural variation in research articles across three engineering sub-discipline corpora. English for Specific Purposes, 37, 74-86.

Kizilcec, R. F., Papadopoulos, K., \& Sritanyaratana, L. (2014, April). Showing face in video instruction: effects on information retention, visual attention, and affect. In Proceedings of the SIGCHI conference on human factors in computing systems (pp. 2095-2102). ACM.

Knezek, L. A. (2015). Academic reading online: Digital reading strategies of graduatelevel English language learners (Doctoral dissertation, University of North Texas).

Kuxhaus, L., \& Corbiere, N. C. (2016). Classroom journal club: collaborative study of contemporary primary literature in the biomechanics classroom. Journal of Biomechanical Engineering, 138(7), 070801.

Liou, H. C., Yang, P. C., \& Chang, J. S. (2012). Language supports for journal abstract writing across disciplines. Journal of Computer Assisted Learning, 28(4), 322-335.

Marriott, P., \& Teoh, L.K. (2012). Using screencasts to enhance assessment feedback: Students' perceptions and preferences. Accounting Education, 21(6), 583-598.

Mayer RE (2001). Multimedia Learning, New York: Cambridge University Press.

Mayer RE (2008). Applying the science of learning: evidence-based principles for the design of multimedia instruction. Cogn Instr 19, 177-213.

Mayer RE, Johnson CI (2008). Revising the redundancy principle in multimedia learning. Br J Educ Psychol 100, 380-386.

Mayer, R. E., \& Moreno, R. (2003). Nine ways to reduce cognitive load in multimedia learning. Educational psychologist, 38(1), 43-52.

Maswana, S., Kanamaru, T., \& Tajino, A. (2015). Move analysis of research articles across five engineering fields: What they share and what they do not. Ampersand, 2, 1-11

McDonough, J., \& Shaw, C. (2012). Materials and Methods in ELT. John Wiley \& Sons. 
Negretti, R. (2012). Metacognition in student academic writing: A longitudinal study of metacognitive awareness and its relation to task perception, self-regulation, and evaluation of performance. Written Communication, 29(2), 142-179.

Negretti, R. (2017). Calibrating genre: Metacognitive judgments and rhetorical effectiveness in academic writing by L2 graduate students. Applied Linguistics, 38(4), $512-539$.

Negretti, R., \& Kuteeva, M. (2011). Fostering metacognitive genre awareness in L2 academic reading and writing: A case study of pre-service English teachers. Journal of Second Language Writing, 20 (2), 95-110.

Negretti, R., \& McGrath, L. (2018). Scaffolding genre knowledge and metacognition: Insights from an L2 doctoral research writing course. Journal of Second Language Writing, 40, 12-31.

Nwogu, K. N. (1997). The medical research paper: Structure and functions. English for Specific Purposes, 16 (2), 119-138.

Peacock, M. (2011). The structure of the methods section in research articles across eight disciplines. The Asian ESP Journal, 7(2), 99-124.

Posteguillo, S. (1999). The schematic structure of computer science research articles. English for specific purposes,

Raimes, A. (1991). Out of the woods. Emerging traditions in the teaching of writing. TESOL Quarterly, 25, 407-430.18(2), 139-160.

Silva, M.L. (2012). Camtasia in the classroom: Student attitudes and preferences for video commentary or Microsoft Word comments during the revision process. Computers and Composition, 29(1), 1-22.

Spantidakis, I., Chatzidaki A., Kourti-Kazouli V., Varsamidou D. \&Chatzipanagotidi A. (2013). Computer Assisted Language Teaching In Greek Language Education and elearning in Diaspora:Design and Devolpment of a Web-based Environment (pp. 39-52). EDIAMME, Rethimno.

Stoller, F. L., \& Robinson, M. S. (2013). Chemistry journal articles: An interdisciplinary approach to move analysis with pedagogical aims. English for Specific Purposes, 32(1), 45-57.

Swales, J. M. (1990). Genre analysis: English in academic and research settings. Cambridge, England: Cambridge University Press.

Swales, J. (2004). Research genres: Explorations and applications. Ernst Klett Sprachen.

Tardy, C. M. (2009). Building genre knowledge. West Lafayette, IN: Parlor Press.

Thompson, R. \& Lee, M. J. (2012). Talking with students through screencasting: Experimentations with video feedback to improve student learning. The Journal of Interactive Technology and Pedagogy, 1 (1).

Urquhart, A. H., \& Weir, C. J. (2014). Reading in a second language: Process, product and practice. Routledge.

Van Lacum, E. B., Ossevoort, M. A., \& Goedhart, M. J. (2014). A teaching strategy with a focus on argumentation to improve undergraduate students' ability to read research articles. CBE-Life Sciences Education, 13(2), 253-264.

Vincelette, E. J., \& Bostic, T. (2013). Show and tell: Student and instructor perceptions of screencast assessment. Assessing Writing, 18(4), 257-277.

Vivian, R., Falkner, K., \& Falkner, N. (2013, March). Building consensus: Students' cognitive and metacognitive behaviours during wiki construction. In Learning and Teaching in Computing and Engineering (LaTiCE), 2013 (pp. 154-161). IEEE. 